Discussion Training in the communication skill of breaking bad news is useful and interesting to medical students. Identifying key strategies to employ whilst breaking bad news, and engaging in role play, improves confidence.

\section{SIMBA STUDY: UNDERGRADUATE MODULE IN SIMULATION TRAINING AND BASIC LIFE SUPPORT TO IMPROVE UNDERGRADUATE CONFIDENCE IN PAEDIATRICS}

doi:10.1136/archdischild-2012-302724.1013

${ }^{1} \mathrm{H}$ Bruell, ${ }^{2} \mathrm{~F}$ McElligott, 'S Vaish, ${ }^{3} \mathrm{~A}$ Savage, ${ }^{1} \mathrm{~A}$ Nicholson, 'E Molloy. ${ }^{1}$ Paediatric Department, RCSI; 'Neonatology, National Maternity Hospital; ${ }^{3}$ Resuscitation Department, Children's University Hospital, Dublin, Ireland

There are significant differences in resuscitation algorithms for children versus adults. We aimed to enhance confidence of our students in the assessment and management of sick children by developing a simple program with emphasis on Basic Airway management, CPR, and clinical assessment and treatment of children using the $\mathrm{A} / \mathrm{B} / \mathrm{C}$ / $\mathrm{D} / \mathrm{E}$ system.

The course consisted of three parts in small group sessions (1015 students):

BLS, basic Airway and Cardiac arrest management, lasting (1.5 h);

DVD and serious illness scenarios on traditional mannequins $(2 \mathrm{~h})$

Serious illness scenarios in the Simulation baby laboratory $(0.5 \mathrm{~h})$.

All participants were given a pre course hand out. The course was led by qualified APLS instructors and student confidence was evaluated by a pre and post course questionnaire.

Pre course $18.8 \%$ of the students would not feel confident to approach a situation with a sick child outside the hospital versus $3.2 \%$ after the course. Three times more Students felt confident manageing a child outside the hospital. Confidence in assessing and managing common paediatric problems in hospital, increased by $22 \%$, with the greatest increase regarding children with respiratory and cardiac problems.

$75 \%$ liked the mixture of lectures and practical sessions. Overall more than $80 \%$ felt they benefitted from all different parts of the course. Confidence to approach, assess and manage a sick child increased by an average of $18.5 \%$.

Medical students found the interactive resuscitation training useful. Formalized simulation and resuscitation training improved medical student confidence and equipped them for in and outof -hospital paediatric management.

\section{HIGHER SPECIALIST TRAINING IN IRELAND. LEARNING FROM THE GRADUATES 2005-2011}

doi:10.1136/archdischild-2012-302724.1014

'BJ Freyne, ${ }^{2}$ AJ Nicholson, 'MB O'Neill. ${ }^{1}$ Paediatrics, Mayo General Hospital, Castlebar; ${ }^{2}$ Childrens University Hospital Temple Street, Dublin, Ireland

Background and Aims The Higher Specialist Training (HST) program in General Paediatrics was initiated in 1999. The first graduates to complete the full program received their CSCST in 2005. There are 15 graduates per year. This study evaluated whether graduates believed core competencies of the HST curriculum were achieved and assessed their perceptions of its strengths and weaknesses.

Methods The lack of an accurate database resulted in a convenience sample being utilized. Demographic data obtained included year of program entry and current position. The survey utilized a Likert scoring system (cuing at 1 , not at all, cuing at 6 , definitely) to evaluate the training process relating to clinical skills, research abilities, health economics. Qualitative questions allowed for personal reflections on the training process both positive and negative. Responses were analyzed for themes.
Results Data were analyzed from a convenience sample of 25 responses (1/3 of all trainees). The M:F ratio was $3: 1$. Twenty three graduates $(92 \%)$ completed overseas fellowships. Mean Likert scores were clinical competency (4.8), basic science knowledge (4.9), evidence based medicine application (3.7), ability to work as academic supervisor (3.3), research skills (2.9), health economics (2.3) and health policy (2.3). Negative themes from qualitative analysis included the adverse impact of excessive service provision on training and the lack of structured career advancement. Most felt clinically competent compared to international colleagues.

Conclusion Clinical competency is achieved through the HST program. Specific training is required for health management, policy and research aspects of training.

\section{UNDERSTANDING THE TEACHING OF PEDIATRICS IN GRADUATION IN MEDICINE IN RIO DE JANEIRO, BRAZIL}

doi:10.1136/archdischild-2012-302724.1015

'EO Veiga, ${ }^{2}$ NA Batista. ${ }^{1}$ Faculdade de Medicina de Petrópolis, Petrópolis; ${ }^{2}$ Universidade Federal de Sao Paulo, São Paulo, Brazil

Background and Aims The movement of transformation through which passes the medical education in Brazil prompted us to understand and describe soma aspects the Pediatric Education in medical undergraduate.

Methods For this we developed an exploratory research, descriptive, cross-sectional quantitative and qualitative approach. We investigated 16 courses and coordinators through semi-structured interviews and institutional documents. It became apparent concern for the context of teaching for all those who participated as study subjects.

Results The total workload of the course in undergraduate Pediatric Medicine held $10.07 \%$ of the total workload of the courses and their integration has occurred from the third year of graduation, with the primary health care settings primarily used in $93.75 \%$ of schools. The teaching plans demonstrate the enhancement of cognitive development in the learning process, with the psychomotor domain and affective ill-favored. The evaluation process found is focused on learning for students leaving a major void in the assessment of own teaching and their teachers. The practical evaluation of the teaching-learning of students is privileged only $18 \%$ of the courses and the assignment of concept is referred to in $87.5 \%$ of courses. We noted the will expressed by various schools and their parents, transformations aimed at improving education.

Conclusion The understanding of the teaching of Pediatrics as a fundamental part of general medical education at undergraduate level may, in our view, contribute to the formulation of projects that encourage the construction of new avenues for improving the teaching-learning process in Pediatrics.

\section{EVALUATION OF LEARNING OPPORTUNITIES DURING PAEDIATRIC ATTACHMENT: AN ONLINE SURVEY OF MBBS5 STUDENTS}

doi:10.1136/archdischild-2012-302724.1016

P Kundasamy, J Blake. St George's Hospital Medical School, London, UK

Aims To ascertain whether the clinical objectives for $4^{\text {th }}$ year medical students on paediatric attachments were being met by evaluating the learning opportunities available to them.

Background Recent research shows a decline in the number of foundation trainees selecting paediatrics. Students have previously described their attachment as too emotional and clinical experience too limited to make an informed choice about paediatrics as one of their career options. There are numerous skills to be learnt over a relatively short period of time. Moreover, skills such as history-taking 